\title{
Sala de Professores ${ }^{1}$
}

\section{Entrevistada: Maria Regina Soares de Lima}

Professora do Instituto de Estudos Sociais e Políticos da Universidade do Estado do Rio de Janeiro (IESP/UERJ), Rio de Janeiro/RJ, Brasil. E-mail: mrslima@iesp.uerj.br

\section{Entrevistadores: Renan Medeiros de Oliveira}

Universidade do Estado do Rio de Janeiro, Rio de Janeiro/RJ, Brasil. E-mail: renanmedeirosdeoliveira@gmail.com

\section{Leandro Carlos Dias Conde}

Instituto de Estudos Sociais e Políticos da Universidade do Estado do Rio de Janeiro (IESP/UERJ), Rio de Janeiro/RJ, Brasil. E-mail: leandrocdconde@iesp.uerj.br

Revista Publicum (RP): Gostaríamos de iniciar perguntando quais foram suas principais motivações para seguir na carreira da docência. A senhora defendeu a sua tese "The Political Economy of Brazilian Foreign Policy: nuclear energy, trade and itaipu", em 1986, na Vanderbilt University, que até hoje é considerado um importante trabalho no campo das relações internacionais brasileiras, que se iniciava no Brasil. Por que escolheu a Ciência Política e, mais precisamente, as Relações Internacionais?

Maria Regina Soares de Lima (MRSL): Eu iniciei na PUC-Rio em 1963, eu me lembro porque eu estava na universidade quando ocorreu o golpe militar de 1964. Desde aquela época eu já gostava muito de história. Estudei em um colégio de freira e, na minha geração, no meu colégio, ou você ia para a universidade ou você constituía família (casar). Eu preferi ir para a universidade - eu e várias outras pessoas. Eu não tinha muita ideia do que fazer, gostava muito de história,

${ }^{1}$ Essa entrevista foi transcrita por Leandro Carlos Dias Conde e editada e revista pelos entrevistadores. O texto final mantém a natureza informal e oral de uma conversa. 
mas quando fui, acabei indo para a sociologia. Era o primeiro ano do curso de sociologia da PUC antes era sociologia e economia. Era 1963, um ano muito fervilhante na política; no ano seguinte teve o golpe. Como eu vinha de um colégio de freiras, não tinha nenhum envolvimento político prévio, mas a universidade mudou a minha vida, trata-se de um efeito enorme de socialização. Tão logo acabei a graduação, tive a sorte de me engajar em pesquisa no antigo IUPERJ, atual IESP, chamada pelo professor Cândido Mendes, que havia sido meu professor, para trabalhar num projeto. Foi assim que eu comecei. Eu era muito jovem ainda, não tinha uma ideia clara de que queria seguir a carreira docente. Eu comecei a trabalhar em pesquisa após ter terminado a graduação e tive, naquele momento, uma oportunidade de ir para a Flacso, a convite do professor Gláucio Soares - isso já no final dos anos 1960 e início dos anos 1970, mas eu não sabia muito bem o que fazer ainda, então terminei o mestrado, e não fui para a Flacso. Surgiu uma oportunidade de ir estudar nos Estados Unidos, e eu fui para Vanderbilt, isso em 1976, mas não fiquei lá, voltei para o Brasil e só retornei aos EUA para a defesa da tese. Então quando fui fazer o doutorado, e voltei ainda sem ter defendido, me inseri no IUPERJ com uma bolsa da Fundação Ford num programa que financiava doutorados em ciência política nos Estados Unidos à época. Como a ciência política estava começando, a Fundação Ford foi muito importante para a consolidação do doutorado no IUPERJ. Durante o período em que estava no Brasil antes de defender em 1986, eu já comecei a dar aulas na pós-graduação do IUPERJ. As coisas foram acontecendo, a opção pela ciência política implicava ensino e pesquisa, não foi por vocação, então foi assim que eu me inseri, mas foi direto na pós-graduação, tanto que quase não tive experiência dando aulas na graduação, até cheguei a ser assistente do professor Cândido Mendes, mas foi tudo um pouco ad hoc. Sempre trabalhei na pós-graduação. Confesso que, no fundo, lecionar na graduação foi algo que me faltou. Mas a vida é assim, vai levando você, não se tem como planejar tudo o que se quer fazer. Assim, eu acabei ficando professora da pósgraduação no IUPERJ e na PUC-Rio - na verdade, eu não tinha muita vontade de fazer concurso para professor.

Como eu escolhi as relações internacionais? Eu não tinha muita ideia no Brasil, eu conheci a disciplina nos Estados Unidos. Durante o curso, as disciplinas que eu mais gostava eram as relações internacionais e política comparada, gostava até mais desta última. Tive ótimos professores de política comparada. Foram essas duas áreas que me atraíram. Acabei fazendo a minha tese sobre política externa brasileira. Novamente, isso criou um envolvimento meu na área de relações internacionais, e, por lá, fiz muitos cursos dentro da área, curso de teoria. Foi aí que comecei a me envolver na área. $\mathrm{O}$ contexto em que me profissionalizei é bastante distinto do de hoje, não havia muita gente, era um grupo pequeno, geralmente com pessoas formadas no 
exterior, e eu, por estar nas relações internacionais, acabei ficando numa comunidade ainda menor do que a comunidade de ciência política.

\section{RP: Como foi seu percurso profissional até chegar à sua posição atual, professora do IESP-UERJ, antigo IUPERJ, tendo também sido professora por muitos anos da PUC-Rio? Na sua inserção profissional, a senhora percebeu alguma dificuldade extra em relação aos seus colegas homens?}

MRSL: A minha inserção nas relações internacionais aconteceu, de fato, quando eu fui para a PUC-Rio, em 1987, logo depois da minha defesa de doutorado. Na PUC-Rio, eu estava na área de relações internacionais, normalmente encarregada dos cursos de teoria das relações internacionais. Já no IUPERJ, eu trabalhava na área de política social, dava muitos cursos com o professor Renato Boschi. Eu tentava dividir a minha carreira nessas duas áreas. Confesso que não me recordo de situações difíceis por ser mulher nos dois ambientes. Primeiro, porque o ambiente na PUC-Rio era formado por pessoas que já tinham sido meus alunos, mas que estavam retornando ao Brasil, como a própria Mônica Herz, que fez mestrado no IUPERJ, sob a minha orientação; e a Letícia Pinheiro, que, embora não tenha feito o doutorado na PUC, mas na London School of Economics, eu já conhecia, porque ela trabalhava no CPDOC da FGV; e havia também o Gerson Moura, uma pessoa encantadora - trabalhamos muito juntos, escrevemos muitas coisas. Então, tanto o ambiente na PUC, quanto o ambiente do IUPERJ, eram ambientes de colegas meus. Entre eles, o Renato Bosque e o Olavo Brasil, que são de uma geração mais nova, a minha geração, mas também o Wanderley Guilherme dos Santos e o César Guimarães, que eram de uma geração mais velha. Essa integração nos dois ambientes foi muito importante para mim.

Talvez eu não me lembre de eventos específicos, porque algumas coisas podem ter sido imperceptíveis. Naquela época era mais comum as mulheres ou acabarem sendo mais tímidas ou mais agressivas; no meu caso, sempre fui mais tímida. É preciso ressaltar que no IUPERJ também tive importantes colegas, já ascendentes na carreira, como a Eli Diniz e a Elisa Reis, então havia mulheres importantes na ciência política do IUPERJ na minha geração. Outro fato que possa ter contribuído é que tanto na PUC-Rio quanto no IUPERJ, eram áreas que estavam sendo construídas, talvez por isso essas diferenças de gênero não apareciam, não se tratava de ambientes já constituídos, com uma longa história passada. Todos faziam parte daquele esforço inicial, e eram pessoas com quem eu tinha muita ligação, era um ambiente diferente do atual. 
A única vez que eu me lembro de uma situação nesse sentido foi na ANPOCS, quando apresentei um paper com a Mônica Hirst, que trabalhava no CPDOC, mas que havia feito o mestrado no IUPERJ. Nós duas sempre tivemos uma ligação muito grande, produzimos muito juntas. Nesse caso específico, nós escrevemos um texto sobre o Tratado de Não Proliferação Nuclear, o TNP, até porque a minha tese tratava dessa questão também. Estávamos apresentando no GT da ANPOCS, e um colega bem tradicionalista, na hora do debate, chamou a atenção questionando como um tema tão árido poderia ser tratado por duas jovens mulheres. Nesse momento, o professor Gerson Moura levantou e, com muita classe, o respondeu à altura. Enfim, isso não é propriamente um caso que relate uma dificuldade na carreira, mas é isso, o preconceito existia. Eu sei que tive muita sorte na minha carreira de não ter enfrentado grandes obstáculos, sobretudo em relação à questão de gênero. As coisas não foram, de alguma forma, tão difíceis. Hoje acho que é mais difícil, porque a concorrência é maior, e acirra esses casos, e a mulher acaba tendo que se impor de alguma forma. Na minha época eram poucas pessoas, e havia uma ligação e espaço para crescer. Confesso que o machismo nunca foi uma questão que eu tivesse sentido diretamente. Eu até tive alguns problemas posteriores com colegas na profissão, até mesmo ex-orientandos, mas não foi, propriamente, devido ao gênero, era mais de embate de ideias, diferenças ideológicas etc.

\section{RP: O presidente eleito tem uma visão muito crítica do Mercosul e da} integração regional. Durante uma entrevista, Paulo Guedes, futuro ministro da economia, disse que a Argentina e o Mercosul "não são prioridades" para a futura gestão do Brasil. Durante as últimas administrações, a integração regional foi uma pauta importante na política externa. Como a senhora vê o papel da região para o Brasil, particularmente do Mercosul?

MRSL: Primeiro precisamos colocar num contexto. Muita coisa que ele disse durante esse tempo, ele mesmo já voltou atrás. Essa tem sido a sua marca, ele diz algo, mas em pouco tempo volta atrás no que disse. Alguns teóricos da comunicação já disseram que isso é uma estratégia de comunicação, algo que Donald Trump faz muito. Eles criam uma notícia, uma situação qualquer, e depois eles vêm com outra verdade, e, quando questionados, acusam a imprensa de fake news, uma vez que a verdade é só o que eles dizem. Pode ter essa estratégia também, mas eu acho que, na verdade, o que se tem é muito desconhecimento. O Bolsonaro claramente tem um perfil 
de delegação, eu acho que ele não tem ideia do que é governar um país como o Brasil, para início de conversa. Ele não tem ideia. Ele sempre foi um político com uma carreira medíocre, que não fez quase nada. Nunca deve ter tido uma ideia de ser presidente, foram as circunstâncias que tornaram viáveis a sua eleição. Em algum momento, os analistas políticos vão ter que explicar como uma pessoa dessas chegou ao poder. Então primeiro há esse lado, de falar algo e voltar atrás.

Certamente, do ponto de vista do economista Paulo Guedes, um hiperliberal, o Mercosul é visto de forma negativa, porque é um acordo nos moldes da União Europeia, que objetiva a criação de um mercado comum, mas que restringe, muitas vezes, a liberdade de cada um dos atores, uma vez que os países não podem fazer acordos comerciais com outros países sem que todos os membros estejam juntos. Então sempre houve uma visão de se construir um grande mercado para as empresas regionais, claramente beneficiando as empresas brasileiras, dado o maior desenvolvimento da indústria nacional. O modelo do Mercosul era a União Europeia, mas ele se tornou praticamente só uma união aduaneira, na qual há livre-comércio intrazona. Ele não conseguiu se consolidar da forma como se pensava inicialmente, mas em função de interesses diversos ao longo dos anos. Porém, ele sempre foi visto como algo que tiraria flexibilidade do Brasil, mas essa visão também já foi compartilhada por outros membros. O Uruguai já teve a intenção de firmar um tratado de livre-comércio com os Estados Unidos e se viu impedido pelas regras do bloco. Então o Mercosul sempre teve muitos críticos nos países membros. A opinião do Paulo Guedes reflete muito dessas críticas. Só que como tantas outras coisas que o Bolsonaro e a sua equipe falam, parece que não houve um cálculo dos impactos de uma decisão dessas. Por exemplo, o fim do Mercosul seria o fim do acordo automotivo entre os membros, o que também seria praticamente o fim das exportações da indústria automobilística brasileira e mesmo da indústria nacional que importa muitas peças dos outros países. É muito pouco provável que a indústria automobilística que tem uma longa tradição de proteção e subsídio vá aceitar uma decisão dessas.

Além disso, isso não é algo muito inteligente. O Mercosul é uma área muito importante para as exportações industriais brasileiras. Uma mudança dessas que regride o Mercosul a somente acordos de livre-comércio afeta a muitos interesses da indústria brasileira. O bloco é muito benéfico para as exportações brasileiras e é como se eles desconhecessem esse fato. Novamente, é mais uma dessas declarações feitas como se a política internacional fosse uma tábula rasa onde se pode fazer qualquer coisa. Não, não se pode, porque há interesses constituídos dentro e fora do país. Pode ser até que esse novo governo consiga flexibilizar uma coisa ou outra, mas no fundo, terminar com o Mercosul significa afetar enormemente a indústria 
automobilística e outras que exportam para os países do bloco, o que vai acarretar na perda de milhares de empregos diretos e indiretos.

Ele vai fazer isso? Eu não sei. Há muitas coisas que eles falam que farão que tem implicações que parece que eles não pensaram. Por exemplo, falar em sair do Acordo de Paris. Imediatamente, o presidente francês, Emmanuel Macron, já fez uma reprimenda à fala de Bolsonaro, avisando que não haverá acordo comercial entre Mercosul e União Europeia com a saída do Brasil do acordo. Por exemplo, a declaração da retirada do convite da realização da COP25 no Brasil pelo Bolsonaro vai na contramão do histórico de participação ativa do país nos acordos climáticos. O Brasil conquistou um grande espaço internacional na área de meio ambiente, nós somos, como diz o embaixador Rubens Ricupero, um global player ambiental pela extensão da floresta tropical, pela imensa biodiversidade, pelas reservas de água potável, ou seja, o Brasil é um ator importante nessa área. Por outro lado, as implicações negativas para as exportações de commodities brasileiras com a saída de acordos de redução de emissão de carbono são muito grandes. Ou seja, essa fala dele, como tantas outras, não faz sentido. O que eu queria chamar atenção é que há muitas contradições, muitas coisas que estão sendo anunciadas têm implicações negativas que parece que eles não levam em conta.

\section{RP: Como a senhora vê as declarações iniciais do presidente eleito de que pretende romper laços diplomáticos com países com governos de esquerda, mudar a embaixada brasileira em Israel para Jerusalém, entre outras? Tais declarações demonstram escolhas políticas ideológicas em contradição com as críticas que ele faz sobre a política externa “ideológica” dos governos PT, não?}

MRSL: Pelas declarações do Bolsonaro e equipe, pelo comportamento dos filhos na viagem recente aos Estados Unidos, como prestar continência para o conselheiro de Segurança Nacional da Casa Branca, John Bolton, já percebemos uma sequência de equívocos. Porém, disso tudo, se há uma linha que parece definida é a busca por um alinhamento com os Estados Unidos. A ideologia que está por trás disso é uma coisa completamente anacrônica, refletida no artigo publicado no blog do futuro chanceler, o Ernesto Araújo, muito calcado nas ideias, ou não-ideias, de Olavo de Carvalho, somado a uma ideologia de direita muito influenciada por Steve Bannon, ex-estrategista-chefe da Casa Branca no governo Trump. Tudo isso dá a ideia de que haverá um 
alinhamento com a política externa dos EUA. Poderíamos dizer que agora a política externa também vai ser ideológica, mas no signo contrário - mas é ideológica, como todas. Porém, ela é ideológica num sentido que faz a sua formulação ser muito diferente, um ponto fora da curva, pois está muito claro, olhando os posicionamentos do futuro ministro. Eles acreditam numa série de ideias equivocadas de que o Trump teria um papel messiânico para impedir a ascensão chinesa que é uma ameaça ao Ocidente. Por que é um ponto fora da curva? Porque toda a política é ideológica, não existe política neutra, seja ela qual for a política. As diferenças com as outras políticas externas é que elas tinham uma visão do lugar do Brasil. O Barão do Rio Branco tinha essa visão! A diferença é que tanto o governo FHC quanto o governo Lula temperavam as suas preferências ideológicas com uma visão pragmática, o que o Max Weber chama de "racionalidade das consequências", isto é, no sentido de agir naquilo que era possível, não com base apenas nos fins últimos, que leva a consequências desastrosas.

Sempre houve esse equilíbrio entre prescrições, um projeto normativo com um lado bastante pragmático, essa tem sido, desde Rio Branco, a política externa brasileira. Com FHC, o sentido da política externa da credibilidade também foi temperado com uma visão mais crítica da ideia da globalização. Assim também no caso dos governos PT, que em várias instâncias o Brasil teve de recuar em função de questões que demandavam uma ação mais pragmática. Por exemplo, no G20 comercial, que o Brasil acabou abandonando a aliança com a Índia e se adequou ao que era o mainstream da tese do Pascal Lamy, ex-Diretor-Geral da OMC. Enfim, sempre teve essa combinação, seja numa política externa mais de credibilidade, como era a do FHC, seja numa política externa mais ativa, mais voltada para o sul, como foi a política externa dos governos PT.

Logo, o que eu acho que está faltando nessas declarações é uma visão pragmática. Tais declarações interessam ao Brasil? Quais são as suas consequências? São perguntas que precisam ser feitas. Todas essas ações de política externa que o Bolsonaro já disse que vai fazer têm consequências negativas para o país. Ele está abrindo mão de políticas nas quais o Brasil pode exercer o seu soft power, como, por exemplo, a política ambiental. O próprio General Mourão já deu uma declaração falando que o Brasil não deveria interferir na "briga" dos outros países. Diferente do Trump, que pode interferir nas questões que quiser, o Brasil não pode. Não somos uma potência nuclear, por exemplo! Esse caso da mudança da embaixada de Israel é um desatino, que já teve efeitos na negativa do Egito em receber chanceler brasileiro. Essa decisão pode ter um grande impacto nas exportações brasileiras de commodities aos países árabes, grandes compradores de proteína animal do Brasil. Ou seja, uma decisão absurda, até o Paraguai já voltou atrás na mudança da embaixada para Jerusalém. As consequências negativas para o 
Brasil podem ser enormes, além do fato de que temos, tradicionalmente, a postura de reconhecimento da Palestina.

Por fim, essas declarações são de quem não sabe nada da geopolítica, de quem não entende o que é geopolítica, muito menos o sistema internacional. Elas não só afetam interesses dos exportadores, mas de várias outras constituencies também. Mais uma vez, o Bolsonaro e a sua equipe dão muitas declarações, mas sem entender a consequência real delas, sobretudo na política externa. Até agora não sabemos como vai ser o estilo de governo dele, mas eu tenho a impressão de que ele vai delegar, espero que não delegue para os filhos, porque assim será um desastre. Eu acho que ainda é cedo para fazermos prognósticos, são muitas forças dentro da equipe do Bolsonaro. E não podemos esquecer que há uma resistência dentro da burocracia que se sente ameaçada com o que promete o novo governo. A Agência Brasileira de Cooperação é um exemplo, como que vai ficar a cooperação na área de saúde, vai afetar burocracias como essas que são montadas para isso? Não se sabe. O alinhamento automático com os Estados Unidos não traz nenhum benefício para o Brasil, e muitos militares sabem disso. Acompanhar cegamente o Trump é um risco, como adotar uma postura de intervenção na Venezuela. Claro que o Brasil pode mudar a sua posição e apoiar o grupo de Lima com o propósito de isolar a Venezuela - o que eu acho que é um grande equívoco. Essas declarações, se se tornarem, de fato, política externa, só atraem consequências negativas, e rompem com uma tradição brasileira de tentar mediar os conflitos, garantir algum consenso entre as partes. Sempre foi uma preocupação brasileira deixar conflitos abertos na região, pois temia-se que isso justificasse uma intervenção. Isso é história do Brasil desde Rio Branco. Quando o Barão se aliou aos EUA, no final do século $X I X$, início do século $X X$, foi porque temia-se que houvesse uma expansão do imperialismo europeu na América do Sul. Ele viu nos EUA uma forma de equilibrar a posição brasileira, claramente um alinhamento pragmático. Mas esse não é o caso do Bolsonaro, muito longe disso.

RP: O presidente eleito tem demonstrado grande admiração pela política externa de Donald Trump, indicando o que pode ser o retorno a um “alinhamento automático" aos Estados Unidos, ao mesmo tempo em que, durante a campanha, teceu muitas críticas às intenções da China no Brasil, nosso principal parceiro comercial. Haveria paralelos históricos na política externa brasileira para as ações que o governo eleito pretende tomar? Para onde parece caminhar a nossa política externa nos próximos 
anos?

MRSL: Nós realmente podemos ter algumas surpresas, mas eu acho que muita coisa que está sendo dita não vai ser implementada, penso que eles vão realmente voltar atrás. Mas se isso tudo realmente se concretizar, o Brasil vai perder espaço no plano internacional, vai perder prestígio, capacidade de interlocução, porque o país vai ser ignorado pelos demais nos espaços de decisão. Não vai ser preciso consultar o Brasil, uma vez que as nossas decisões seguem as dos Estados Unidos. Eu me lembro do que disse o Ronaldo Sardemberg, que foi um dos assessores do Azeredo da Silveira, ministro das Relações Exteriores no governo de Ernesto Geisel, na época do pragmatismo responsável: o Brasil tinha uma política muito alinhada aos Estados Unidos nos governos anteriores e isso começou a mudar quando eles perceberam que o Brasil estava sempre sozinho nas votações acompanhando os EUA, e só quem sempre acompanha Washington são países praticamente irrelevantes no sistema internacional. Quando se tem um alinhamento automático tão incondicional, acaba-se ficando sozinho, e a sua opinião não vale de nada, porque ela reflete a opinião dos Estados Unidos. Para se ter credibilidade e capacidade de mediação é preciso ter uma certa neutralidade e pragmatismo - fora alguns momentos como na Segunda Guerra Mundial com o Dutra, que foi uma política muito alinhada, mas em função de um contexto muito peculiar. Os aliados ganharam a guerra e o Brasil foi o único sul-americano a mandar tropas, então o país tinha uma expectativa de que receberia algum benefício no plano internacional, mas não recebeu. No governo Collor também se tentou uma espécie de alinhamento, mas nem ele teve coragem de chegar a tal ponto de incondicionalidade, como fez a Argentina com as relações carnais. Nós nunca tivemos relações assim com os Estados Unidos, sempre houve momentos de alinhamento, mas que em pouco tempo se mostraram caminhos equivocados. A nossa posição sempre foi de equidistância. Algumas vezes entramos em conflito, como no caso Geisel do acordo nuclear com a Alemanha. O ponto é que não temos a tradição de um alinhamento do tipo, mesmo nos períodos em que o alinhamento era radical, não demorávamos a voltar a um equilíbrio.

Então, eu acho que não vai funcionar esse alinhamento como se anuncia. Mas também não sabemos para quem ele vai delegar a política externa, se for para o chanceler, estamos mal, porque ele não parece que tem ideia do que é o mundo, para ele é o que pensa o Olavo de Carvalho, que é um intelectual farsante. Então qual vai ser a política? Os militares que vão ficar responsáveis? Todos esses indicados aos ministérios foram comandantes das forças de paz do Brasil. Segundo declarações do ex-ministro Celso Amorim, são generais que foram escolhidos, naquela época, porque tinham muita experiência para conduzir as missões. São pessoas que tem uma carreira enquanto militares, então não tomariam decisões que colocariam o Brasil em risco.

Revista Publicum

Rio de Janeiro, v. 4, n. 2, 2018, p. 1-10.

http://www.e-publicacoes.uerj.br/index.php/publicum DOI: $10.12957 /$ publicum.2018.38767 
Mas não sabemos para quem ele vai delegar. A delegação pode ser boa para impedir coisas absurdas ou pode ser ruim, a depender de quem for escolhido. O que me impressiona é a falta de compreensão dele do que é governar um país, da necessidade de ter capacidade de coordenação de diferentes setores, que a sua decisão nem sempre é a que vai ser implementada, muito menos da forma como se esperava. O ex-presidente Lula reclamava muito disso, de que ele decidia muitas coisas, mas que elas acabavam não sendo implementadas. Enfim, a burocracia é lenta, são muitas engrenagens, e a resistência burocrática a várias dessas políticas vai ser muito grande. O que vai resultar disso? Não sabemos! 